\title{
Cardiovascular and inflammatory mechanisms in healthy humans exposed to air pollution in the vicinity of a steel mill
}

Premkumari Kumarathasan ${ }^{1,2^{*}}$ (D), Renaud Vincent ${ }^{1,3^{*}}$, Erica Blais ${ }^{1}$, Agnieszka Bielecki ${ }^{1}$, Josée Guénette ${ }^{1}$, Alain Filiatreault ${ }^{1}$, Orly Brion', Sabit Cakmak', Errol M. Thomson' ${ }^{1}$, Robin Shutt ${ }^{1}$, Lisa Marie Kauri', Mamun Mahmud', Ling Liu' and Robert Dales ${ }^{1}$

\begin{abstract}
Background: There is a paucity of mechanistic information that is central to the understanding of the adverse health effects of source emission exposures. To identify source emission-related effects, blood and saliva samples from healthy volunteers who spent five days near a steel plant (Bayview site, with and without a mask that filtered many criteria pollutants) and at a well-removed College site were tested for oxidative stress, inflammation and endothelial dysfunction markers.
\end{abstract}

Methods: Biomarker analyses were done using multiplexed protein-array, HPLC-Fluorescence, EIA and ELISA methods. Mixed effects models were used to test for associations between exposure, biological markers and physiological outcomes. Heat map with hierarchical clustering and Ingenuity Pathway Analysis (IPA) were used for mechanistic analyses.

Results: Mean $\mathrm{CO}, \mathrm{SO}_{2}$ and ultrafine particles (UFP) levels on the day of biological sampling were higher at the Bayview site compared to College site. Bayview site exposures "without" mask were associated with increased ( $p<$ 0.05) pro-inflammatory cytokines (e.g IL-4, IL-6) and endothelins (ETs) compared to College site. Plasma IL-1 $\beta$, IL-2 were increased $(p<0.05)$ after Bayview site "without" compared to "with" mask exposures. Interquartile range $(\mathrm{IQR})$ increases in $\mathrm{CO}$, UFP and $\mathrm{SO}_{2}$ were associated with increased $(p<0.05)$ plasma pro-inflammatory cytokines (e.g. IL-6, IL-8) and ET-1 ${ }_{(1-21)}$ levels. Plasma/saliva BET-1 levels were positively associated $(p<0.05)$ with increased systolic BP. C-reactive protein (CRP) was positively associated $(p<0.05)$ with increased heart rate. Protein network analyses exhibited activation of distinct inflammatory mechanisms after "with" and "without" mask exposures at the Bayview site relative to College site exposures.

Conclusions: These findings suggest that air pollutants in the proximity of steel mill site can influence inflammatory and vascular mechanisms. Use of mask and multiple biomarker data can be valuable in gaining insight into source emission-related health impacts.

\footnotetext{
* Correspondence: premkumari.kumarathasan@canada.ca;

renaud.vincent@canada.ca

${ }^{1}$ Environmental Health Science and Research Bureau, Environmental and

Radiation Health Sciences Directorate, HECSB, Health Canada, Ottawa, ON,

Canada

Full list of author information is available at the end of the article
}

(c) The Author(s). 2018 Open Access This article is distributed under the terms of the Creative Commons Attribution 4.0 International License (http://creativecommons.org/licenses/by/4.0/), which permits unrestricted use, distribution, and reproduction in any medium, provided you give appropriate credit to the original author(s) and the source, provide a link to the Creative Commons license, and indicate if changes were made. The Creative Commons Public Domain Dedication waiver (http://creativecommons.org/publicdomain/zero/1.0/) applies to the data made available in this article, unless otherwise stated. 


\section{Background}

Increased air pollution levels are associated with increased cardio-respiratory morbidity and mortality [5, 17, 53]. Air pollution exposures are also known to elevate the risk of stroke, Alzheimer's like pathology, mood disorders, gastrointestinal disorders, and adverse birth outcomes $[8,16,28,45,74]$. The global burden of diseases study estimated that exposure to ambient $\mathrm{PM}_{2.5}$ led to about 3 million deaths and 84 million disability adjusted life years lost due to ischemic heart disease, acute low respiratory infections and etc. [78].

Toxicity of ambient air particulate matter [1] can be influenced by their physicochemical properties. Source emissions and subsequent atmospheric transformation are determinants of physicochemical characteristics of air particles. It is critical to understand the contribution of different sources to air pollutant toxicity for mitigation purposes. For instance, traffic-related air pollution has been shown to impact on the autonomic control of the heart and heart rate variability [59]. Fixed-site industrial sources have also been linked with adverse health effects. Namely, increased $\mathrm{PM}_{2.5}$ emissions from a local steel mill in the Utah Valley were associated with increased hospital admissions for respiratory illness and decreased lung function in children [51, 52]. A strong association between children's respiratory health and air pollution was shown through examination of a Children's cohort in Hamilton, Ontario, where two largest steel mills in Canada are present [55]. Recently, we have shown that air pollution levels in the vicinity of a steel mill can alter pulmonary function and cardiovascular physiology in healthy adults $[6,10,43,60]$. Moreover, decreased mortality rates have been reported with a copper smelter strike and reduced ambient sulfate particulate matter air pollution [54].

Notwithstanding the strong evidence for adverse health impacts of ambient air pollutants, there remain important knowledge gaps in our understanding of the toxicity mechanisms and the biological plausibility of adverse health outcomes [26]. Such investigations can become challenging due to the complexity of air pollutant mixtures [67].

Squadrito et al., 2001 [65] reported that air particles, namely $\mathrm{PM}_{2.5}$ contained abundant persistent semiquinone radicals. These radicals can contribute to redox cycling reactions and thus oxidative stress conditions in vivo. Inhalation exposure to ozone or ozone-particle mixtures can lead to the generation of reactive oxygen and nitrogen species in animal models $[33,35,36,38,42]$. Acute inhalation of air particles are reported to trigger oxidative stress, inflammation, autonomic and arrhythmogenic effects in heart failure-prone rats [9]. Similarly, inhalation of ozone and ambient air particles are known to cause increased levels of circulating potent vasoconstrictor peptide endothelin (ET)-1 in rats and humans [3, 7, 36, $38,72,75,76]$.

The objective of this study was to identify any mechanistic changes relevant to cardiovascular and inflammatory pathways in healthy adults who inhaled ambient air in the vicinity of a steel mill. The subjects from a randomized crossover study who were exposed to air pollution near a steel plant site (Bayview site) and a site (College site) well removed from the fixed source emissions [10] were assessed for biochemical and physiological changes. In addition, a mask was used to filter out many of the criteria pollutants (e.g $\mathrm{PM}_{2.5}$, ozone) at the steel plant site, to test for any changes due to relatively reduced air pollutant matrix. We hypothesize that, 1 . exposure to increased levels of complex air pollutant mixtures can modify biochemical pathways and thus can affect associated physiological measures; 2. mask, by filtration of most criteria pollutants can reduce the levels and complexity of the air pollutant mixture and can permit the characterization of inter-pollutant interactions. Multiple target proteomic and metabolite markers were measured in saliva and plasma samples. Statistical analyses were conducted to test for exposure site-, mask- and individual air pollutant-related biomarker changes, and to identify any associations between these biomarker levels and physiological measures namely, blood pressure and heart rate. Additional bioinformatic tests using a systems biology approach were conducted to gain insight into source emission exposure-related mechanistic changes at the molecular level.

\section{Methods}

\section{Materials}

Dulbecco's phosphate-buffered saline (PBS, calcium and magnesium free), ethylenediaminetetraacetic acid (EDTA), diethylenetriaminepentaacetic acid (DETPA), phenylmethylsulfonyl fluoride (PMSF), trifluoroacetic acid (TFA), 3,4-dichloroisocoumarin, molecular weight cut-off filters (30, 50 and $100 \mathrm{kDa})$ and endothelins (Big ET-1(BET-1), ET-1, ET-2, ET-3) were purchased from Sigma (St. Louis, MO, USA). Reagent-grade acetone, acetonitrile, ethyl acetate, and methanol were from commercial suppliers. Butylated hydroxytoluene (BHT) was from United States Biochemical Corporation (Cleveland, OH, USA). Deionized water (DI water) was obtained from a super-Q plus high purity water system (Millipore, Bedford, MA, USA). UHP-grade compressed nitrogen was supplied by Matheson Gas products (Whitby, ON, Canada). Amber glass vials and screw caps with septa were purchased from Chromatographic specialities Inc. (Brockville, ON, Canada). Antiprotease (Halt protease inhibitor) cocktail was obtained from ThermoFisher (Ottawa, ON, Canada). Polyclonal 8 -iso-PGF- $2 \alpha$ antibody was purchased from Oxford Biomedical Research (Oxford, MI). The EIA assay kit for free 8 -isoPGF-2 $\alpha$ analysis was from Cayman Chemical 
Company (Ann Arbor, MI). Multiplex kits were purchased from either Millipore (Billerica, MA, USA) or BioRad (Mississauga, ON, Canada).

\section{Study population and design}

A randomized cross-over study was conducted in Sault Ste. Marie, Ontario, Canada, in the summer of 2010 as described by Dales et al., 2013 [10]. The study was approved by the Health Canada Research Ethics Board and the ethics board of Algoma University, Ontario, Canada. In brief, subjects were primarily college students recruited in the city of Sault Ste. Marie, Ontario. This study cohort $(n=52)$ consisted of both men and women of 18 to 34 years of age (5th to 95th percentile) who did not use medications that could affect inflammation or cardio-pulmonary function and who did not have a history of chronic disease, specifically cardiovascular, respiratory and metabolic disorders, nor seasonal allergies, were healthy non-smoking, and without cigarette smoke exposure at home, as well as consented to provide blood samples for analysis. Exclusion criteria included: pregnant or breast-feeding women, and subjects living in the residential neighborhood bordering on the steel plant.

Each subject was randomized to spend 5 consecutive 8-h days (between 7:50 am and 5:50 pm) on the periphery of a residential neighborhood (Bayview Site) adjacent to a steel plant within $0.87 \mathrm{~km}$ of continuously operating coke ovens, or on a college campus (College site) $4.54 \mathrm{~km}$ away from this site or were fitted with a $3 \mathrm{M}$ industrial personal air filter system (3 M Canada Inc., London, ON, Canada) only at the Bayview site (Bayview-Mask). Randomization was done using Excel software based on subject identification number. The exposure design is provided in Table 1.

The filters on the $3 \mathrm{M}$ industrial personal air filter system (Helmet:MP330-105 General-Purpose Headgear Assembly; Motor: Breathe-Easy Turbo 022-00-03;Battery: 3 M 520-01-02R01; Filter: 4530301 OVPF (a combined HEPA and organic vapour filter), removed $98 \%$ of ozone, close to $99.9 \%$ of $\mathrm{NO}_{2}$, and $95 \%$ of $\mathrm{NO}, 99 \%$ of $\mathrm{SO}_{2}$, and $99.97 \%$ of particles of $0.3 \mu \mathrm{m}$ size and only $1 \%$ of $\mathrm{CO}$ (The filters were tested for their performance in our laboratory and the results were consistent with the company's specifications). Also, in general, these study subjects were crossed over between exposure conditions with a 9-d washout period (starting on Saturday through the week and the accompanying weekend until the Monday exposure). The subjects were sedentary mostly during the exposure period, except for a once daily $30 \mathrm{~min}$ period of exercise on an elliptical trainer to increase their heart rate to $60 \%$ of their predicted maximum value (scheduled to occur between 10:30 am and 1:40 pm). The subjects were protected from sun exposure and precipitation by an overhead awning at each location.

\section{Exposure assessment}

Air pollutant measurements were made hourly between $8 \mathrm{~h}$ and $18 \mathrm{~h}$ by a fixed site ambient air quality monitor (Air Pointer ${ }^{\circ}$ Recordum Messtechnik GmbH, Mödling, Austria). This included analyses of $\mathrm{PM}_{2.5}$ (mass median aerodynamic diameter $<2.5 \mu \mathrm{m}$ ) by nephelometry, UFP by a TSI ${ }^{\circ}$ Model $3007(0.01-1 \mu \mathrm{m})$ Ultrafine particle Counter (http://www.tsi.com/condensation-particle-counter-3007/ ), sulphur dioxide $\left(\mathrm{SO}_{2}\right)$ by ultraviolet fluorescence, nitrogen dioxide $\left(\mathrm{NO}_{2}\right)$, nitrogen oxides $\left(\mathrm{NO}_{\mathrm{x}}\right)$ by chemiluminescence, ozone $\left(\mathrm{O}_{3}\right)$ by ultraviolet photometry, temperature and relative humidity, at each location.

\section{Physiological measures}

Cardiovascular parameters were measured in the study subjects [43]. Both systolic and diastolic blood pressure and pulse rate measurements were made $2 \mathrm{~h}$-post arrival (morning), immediately-post exercise and 5 h-post arrival (afternoon).

\section{Biological samples}

Both saliva and blood samples $(n=52)$ were collected late in the afternoon (between 2 and $5 \mathrm{pm}$ ) at the end of the exposure week (Friday) at both College and Bayview sites. Baseline sample was collected for both saliva and blood one week prior (Friday between $2 \mathrm{pm}$ and $5 \mathrm{pm}$ )

Table 1 Sequence of exposure patterns followed in this study for all 4 cohorts

\begin{tabular}{llllll}
\hline & 1st Exposure & Washout & 2nd Exposure & Washout & 3rd Exposure \\
\hline Sequence & (5 days) & Period (days) & (5 days) & Period (days) & (5 days) \\
1 & A & 9 & B & 9 & C \\
2 & B & 9 & C & 9 & 9 \\
3 & C & 9 & A & 9 & A \\
4 & A & 9 & C & 9 & B \\
5 & B & 9 & A & 9 & C \\
6 & C & 9 & B & A
\end{tabular}

Note: Cohorts 1-4 were spaced by time and the entire exposure took place from May-August 2010

$A$ Bayview Mask, $B$ Bayview Ambient (without mask) and C College 
to the beginning of the sequence of exposures. Saliva samples obtained by rolling two cotton rolls in the mouth, one at a time, for $3 \mathrm{~min}$, were transferred into separate Salivette tubes (Sarstedt part\# 51.1534, Sarstedt, QC, Canada) containing PMSF and EDTA. These were centrifuged at $1000 \mathrm{~g}$ for $5 \mathrm{~min}$ and the paired supernatants were pooled. Time-matched blood samples were collected in vaccutainer tubes containing PMSF (final, $1.7 \mathrm{mg} / \mathrm{ml}$ ) and EDTA (final, $10 \mathrm{mg} / \mathrm{ml}$ ) and vortexed to stabilize endothelins a class of vasoconstrictor peptides [34]. Whole blood samples were centrifuged at $1448 \mathrm{xg}$ for $10 \mathrm{~min}$ to obtain plasma. Both blood plasma and saliva samples were shipped from the exposure site to our laboratory on dry ice, and stored at $-80^{\circ} \mathrm{C}$ until further use.

Frozen plasma samples were thawed on ice and vortexed with $20 \mu \mathrm{L}$ of aqueous $0.1 \mathrm{M}$ DETPA solution and $20 \mu \mathrm{L}$ of $0.3 \mathrm{M}$ BHT solution in isopropanol and $10 \mu \mathrm{L}$ of antiprotease cocktail to prevent any post-processing changes due to autoxidation [37]. Aliquots $(250 \mu \mathrm{L})$ of plasma were used for 8 -iso-PGF2 $\alpha$ (8-isoprostane) analysis, while another set was used for analysis of circulating endothelin isoforms (Big ET-1, ET- $1_{1-21}$, ET-2 and ET-3) after treatment with 3,4-dichloroisocoumarin in isopropanol and antiprotease cocktail $(10 \mu \mathrm{L})$. A third set of plasma samples were analysed for inflammatory cytokines, chemokines, and acute phase proteins. Saliva samples thawed on ice were treated with 3,4-dichloroisocoumarin in isopropanol and antiprotease cocktail $(28 \mu \mathrm{L})$ for endothelin isoforms analyses. All plasma and saliva biological endpoints analyses were conducted in duplicates.

\section{Salivary endothelin analyses}

All endothelin isoform analyses were conducted following the procedure described by Tane et al., 1995 [70] using ELISA kits from Phoenix Airmid Biomedical (Canadian supplier for IBL Japan, Oakville, Ontario, Canada). For ET- $1_{1-21}$, ET- $1_{1-31}$ and ET-3 analyses $100 \mathrm{uL}$ aliquots of saliva were used. For BET-1 analysis, samples were diluted 10X. Aliquots of saliva samples and the corresponding lyophilized peptide calibration standards were serially diluted two times and were transferred into separate wells in a primary antibody pre-coated plate, and were incubated overnight $(16-24 \mathrm{~h})$ at $4{ }^{\circ} \mathrm{C}$. The plates were then washed with $0.05 \%$ Tween 20 in $40 \mathrm{X}$ phosphate buffer, and were treated with $100 \mu \mathrm{L}$ of detection antibody and were incubated for $16-24 \mathrm{~h}$ at $4{ }^{\circ} \mathrm{C}$. These samples were then washed and treated with $100 \mu \mathrm{L}$ of chromogen, incubated at room temperature for $30 \mathrm{~min}$, were quenched with $1 \mathrm{~N}$ $\mathrm{H}_{2} \mathrm{SO}_{4}$ solution and were read at $450 \mathrm{~nm}$ using a colorimetric assay reader.

\section{Circulating endothelin isoforms in plasma}

This procedure was conducted as described by Kumarathasan et al., 2001b [34]. Stabilized plasma samples were de-proteinized with acidified acetone, cleaned up using molecular weight cut-off filters $(30 \mathrm{kDa})$, dried under $\mathrm{N}_{2}$ flow, reconstituted in the mobile phase A (composition is given below), and were analyzed by a reversed phase HPLC-Fluorescence system. Initial separation of endothelin isoforms (Big ET-1, ET- $1_{1-21}$, ET-2 and ET-3) were carried out on a LC-318 column $(25 \mathrm{~cm}$ length, $4.6 \mathrm{~mm}$ id, $5 \mu \mathrm{m}$ particle size; Supelco, Oakville, $\mathrm{ON})$ by gradient elution using water-acetonitrile mobile phase (A-30\% acetonitrile (aq); B-90\% acetonitrile (aq)) with $0.19 \%$ of TFA used as the ion-pair reagent. Analytes were measured by fluorescence detection at excitation and emission wavelengths of $240 \mathrm{~nm}$ and $380 \mathrm{~nm}$, respectively.

\section{Affinity-based multiplexed targeted proteomic analyses}

Analysis of human plasma samples for acute phase proteins relevant to cardiovascular diseases [C-reactive protein (CRP), haptoglobin, fibrinogen, platelet factor (PF4), adiponectin, vonWillebrand Factor (vWF), $\alpha_{2}$-macroglobulin (A2M), $\alpha$-acid glycoprotein (AGP), serum amyloid protein (SAP), L-selectin)], and cytokines [interleukins (IL-1, - 2,-4,-5,-6,-7, - 8,-10, - 12, - 13), tumour necrosis factor (TNF- $\alpha$ ), granulocyte macrophage colony-stimulating factor (GMCSF) and interferon gamma (IFN- $\gamma$ )] were done by affinity-based multiplex protein array assays using Bio-Plex Pro Human panels (Biorad) and Milliplex Map kits (Millipore) with a Bioplex 100 instrument (Biorad), based on the procedure reported by Kumarathasan et al., 2014 [37].

\section{Plasma 8-iso-PGF-2a}

Aliquots of plasma $(250 \mu \mathrm{L})$ samples were stabilized with DETPA and BHT to prevent any autoxidation during the 8 -iso-PGF- $2 \alpha$ commonly known as 8 -isoprostane (8-ISOP) analysis. These samples were then de-proteinized, clarified with ethyl acetate and affinity purified by using a polyclonal 8 -iso-PGF- $2 \alpha$ antibody following the procedure described by Bielecki et al., 2012 [2]. Purified plasma samples were then analyzed for 8-iso-PGF-2 $\alpha$ using the EIA kit from Cayman chemical (Ann Arbor, Michigan).

\section{Statistical analyses}

Descriptive statistics was done for air pollution levels on Fridays at College and Bayview site and the pollution levels averaged over 5 days at these sites. Also, IQR values were determined based on data collected on Fridays, and it is equal to the difference between 75 th and 25th percentiles, in other words, between upper and lower quartiles, $I Q R=Q_{3}-Q_{1}$. The mean and 95\% CI are reported for the mean values. We computed the $95 \%$ confidence interval for the mean with the following formula: Lower $95 \%$ limit $=$ Mean $-\mathrm{T}_{.95} \sigma_{\mathrm{M}}$; Upper $95 \%$ limit $=$ Mean $+\mathrm{T}_{.95} \sigma_{\mathrm{M}}$. Where, $\mathrm{T}_{.95}$ is the number of 
standard deviations extending from the mean of a Tdistribution required to contain 0.95 of the area and $\sigma_{M}$ is the standard error of the mean.

Associations among the various saliva and plasma markers were tested by Spearman Rank Order Correlation analyses for all data. Further statistical analyses using mixed effect model testing were conducted to assess the influence of exposure conditions (College site, Bayview site "with" and "without" mask) and criteria air pollutant (CO, NO, $\mathrm{NO}_{2}, \mathrm{NO}_{\mathrm{x}}, \mathrm{O}_{3}, \mathrm{PM}_{2.5}, \mathrm{SO}_{2}$, UFP) levels on plasma and saliva endpoints and physiological endpoints (blood pressure BP and heart rate HR), adjusting for various confounders. The types of associations tested using statistical models are as follows. Test 1. Biomarker levels for Bayview site (ambient, "without" mask) vs College site exposures (site only); Test 2. Biomarker levels for Bayview site ("with" mask) vs College site exposures (site only); Test 3. Biomarker levels for Bayview site (ambient, "without" mask) vs Bayview site ("with" mask) exposures; Test 4. Association between individual air pollutant levels (daily average for Fridays) and biomarkers; Test 5. Exposure type-related differences in physiological (Friday data) measures (Note: Here, corrections for any changes in these measures (e.g systolic BP) associated due to simply wearing the mask, was removed prior to carrying out these comparisons. For this purpose, profiles of each physiological measure (y axis) for with and without mask exposure conditions were plotted against air pollutant levels $(x$ axis) on all five days/exposure week, for each air pollutant. The curves for "with" and "without" mask exposures at the Bayview site were extended to $\mathrm{x}=0$, and the difference $(\Delta)$ between the two curves were determined to assess the pure "mask" effect on these physiological measures. The pure "mask" effect " $\Delta$ " value calculated for each physiological measure was in the same order of magnitude irrespective of the air pollutant, suggesting that it is almost a constant measure and a reasonable estimate of the pure "mask" effect. For each physiological measure, the " $\Delta$ " value for all air pollutants were thus averaged, and the " $\Delta_{\text {avg }}$ " value was subtracted from the physiological measures for the "with" mask exposures (daily average for Fridays), prior to carrying out comparisons of physiological measures by exposure type); Test 6 . Individual air pollutant levels (daily average for Fridays) vs physiological measures; Test 7. Biomarker levels vs physiological measures.

The subject-specific mean air pollution exposures (daily averages, Fridays) were calculated as averages of air pollution levels from time the subject arrived at the study site until time of blood or saliva sample collection. For each saliva and blood endpoint, we conducted descriptive statistics, for the complete dataset and for each exposure level separately. All plasma and saliva markers showed skewness in the data points and were log-transformed prior to modelling to attain normality, with the exception of physiological endpoints (BP and HR). Mixed effects models with Restricted Maximum Likelihood (REML) estimation were employed in these analyses. The exposures and the air pollution levels were treated as fixed effects, and the study participants were treated as random effects. The subjects with masks were not included in the statistical analyses conducted to identify air pollution-related effects, since air pollutant levels under the mask were not measured. The subjects with masks at the Bayview site were only included when exposure site-related effects were tested. An additional random effect of date was examined to reflect the fact that there were four study cohorts present at the study sites on different sets of days.

The models were adjusted for various sets of candidate covariates: date of exposure, carry-over effect (since the same subjects were exposed to the different conditions after one week wash out period), age, sex, body mass index (BMI), ambient air pressure, humidity and temperature.

Baseline observations for plasma and saliva endpoints prior to the exposure regimen were considered as covariates in the model since air pollution measurements were not available. Blood pressure and heart rate measurements considered in these analyses are medians of five readings taken on Friday afternoons around the time when the plasma samples were obtained as well. Note: Biomarker changes (on Fridays of the exposure week) due to exposure at the Bayview site "without" mask (ambient) or at the Bayview site "with" mask, were tested separately against College site exposures. The Akaike Information Criterion was used to choose the best-fitting models. All data management and modelling were conducted in SAS EG 4.2 (Cary, NC, USA) and R version 2.15.1 (The R Foundation for Statistical Computing). Statistical significance was considered at $p<0.05$.

We also normalized the biomarker level for each subject at different exposure conditions by the average values for this subject during the study period to adjust for individual variability. This information was used to conduct following bioinformatics analyses. Heat map with hierarchical clustering was employed to visualize differential pattern of plasma marker responses as a result of the different exposure scenario. The analysis was done using the hierarchical clustering option in GenePattern (http://genepattern.broadinstitute.org/gp/pages/ login.jsf), and formatted in Java treeview (http://jtreeview.sourceforge.net/). Furthermore, Ingenuity Pathway Analysis (IPA) (Ingenuity Systems, www.ingenuity.com) was used to analyse for protein interaction networks, biofunctions and disease pathways using the normalized data. Fold change values (average marker response at Bayview site (with or without mask)/average marker response at the College site) were used for this purpose, 
and only the protein markers that were significant based on the above mentioned statistical analyses results were included for this analysis.

\section{Results}

\section{Characteristics of the study population}

The results described here are from 52 subjects (both males and females) who participated in the entire exposure study, and consented to blood draws. Characteristics of the study subjects are shown in Table 2. Most of the study subjects were Caucasian, and the average age was 23 yrs. Most of the study subjects exhibited normal systolic $(<120 \mathrm{mmHg})$ and diastolic $(<80 \mathrm{mmHg})$ blood pressure values. Also, the BMI values suggest that most of the subjects were not obese by definition $\left(<30 \mathrm{~kg} / \mathrm{m}^{2}\right)$.

\section{Exposure}

Temperature, relative humidity and air pressure at the two study sites were similar [10] for Fridays of the week during this study period. Nevertheless, air pollutant levels at the Bayview site especially in terms of $\mathrm{SO}_{2}$, $\mathrm{NO}_{2}, \mathrm{NO}_{\mathrm{x}}, \mathrm{CO}$ and UFP levels were different compared to that at the College site as stated in our previous reports (Table 3). Briefly, at the Bayview site $\mathrm{SO}_{2}$ was increased about four-fold, while $\mathrm{CO}, \mathrm{NO}_{\mathrm{x}}$ and UFP levels were increased about 2-3 fold compared to that at the College site. These Friday measurements are not statistically significantly different from all other days (Additional file 1: Table S2). We have also provided the Air Quality Health Index (AQHI) values for Canada.

\section{Inter-relationships among different biomarkers}

The Spearman Rank Order correlation analysis on plasma and saliva end points to assess the relationships between the different biological endpoints in these subjects revealed associations between salivary and plasma endothelins. Salivary BET-1 was correlated with plasma BET-1 ( $p=0.05, r=0.153)$. Plasma BET-1 was seen to be positively associated with circulating lipid oxidation

Table 2 General characteristics of the study subjects

\begin{tabular}{ll}
\hline Participant Characteristics & Median \\
\hline Age (year) (5th- 95th percentile) & $23.0(18-34)$ \\
Sex, female/male (number) & $28 / 24$ \\
Body Mass Index $\left(\mathrm{kg} / \mathrm{m}^{2}\right)$ (5th- 95th percentile) & $25.3(19.6-35.5)$ \\
Ethnicity, Caucasian/other (number) & $44 / 8$ \\
$\begin{array}{l}\text { Baseline Systolic Blood Pressure }(\mathrm{mmHg}) \\
\text { (5th - 95thpercentile) }\end{array}$ & $106.5(92.5-128.5)$ \\
$\begin{array}{l}\text { Baseline Diastolic Blood Pressure ( } \mathrm{mmHg}) \\
\text { (5 } 5^{\text {th }} \text { 95th percentile) }\end{array}$ & $68.0(57.9-85.9)$ \\
Baseline Heart Rate (bpm) (5th- 95th percentile) & $73.2(58.4-92)$ \\
\hline
\end{tabular}

marker 8-ISOP ( $p=0.05, r=0.158)$ and plasma ET- $1_{1-21}$ was negatively correlated $(p<0.05, \quad r=0.225)$ with 8-ISOP. Plasma ET- $1_{1-21}$ was also found to be negatively correlated $(p<0.05, r \geq 0.178)$ with the acute phase proteins AGP, fibrinogen, SAP and haptoglobin. Plasma BET-1 was positively associated with PF4 $(p<0.05, r=$ 0.205). Acute phase proteins AGP, fibrinogen, SAP, PF4, adipsin, vWF and haptoglobin were positively correlated $(p<0.05, r \geq 0.270)$ with each other except for adiponectin. The acute phase proteins AGP, fibrinogen, SAP and haptoglobin were positively associated $(p<0.05, r \geq$ $0.154)$ with IL-7, IL- 8 , IL- 12 , TNF- $\alpha$ and IFN- $\gamma$. These correlation coefficients were weak to modest.

\section{Statistical model results Biomarker profiles}

Bayview "without" mask (ambient) vs college site (site only analyses) Relative changes in the biomarker responses at the two sites (Test 1) are shown in Table 4 . Bayview site ambient exposures were associated with increased $(p<0.05)$ cytokines (e.g. IL-4, IL-6, TNF- $\alpha$ ), saliva/plasma endothelins (e.g. BET-1, ET-1 $1_{(1-21)}$, ET-3) and adiponectin compared to the College site (Table 4). Whereas, plasma AGP, haptoglobin and vWF are decreased $(p<0.05)$ with exposures at the Bayview site (ambient) compared to the College site. In addition, plasma ET-1 $1_{(1-21)}$, IL-1 $\beta$, CRP and saliva ET-3 levels exhibited an increasing trend $(p<0.1)$, while plasma A2M and PF-4 showed a decreasing trend $(p<0.1)$ with exposures at the Bayview site (ambient) compared to the College site.

Bayview "with"mask vs college site (site only analyses) The model results (Test 2) showed increased $(p<$ $0.05)$ TNF- $\alpha$, saliva BET- 1, ET- $1_{1-21}$ levels and decreased $(p<0.05)$ levels of AGP, haptoglobin, vWF and IL-2 levels after exposure at the Bayview site (with mask) compared to the College site.(Table 5) In addition, increasing trend $(p<0.1)$ in IFN $\gamma$, IL-4, IL-8, plasma ET- $1_{1-21}$, ET-3 and saliva ET- $1_{1-31}$ levels and a decreasing trend $(p<0.1)$ in PF-4 and SAP levels are seen with exposures at the Bayview site (with mask) compared to the College site (Table 5).

Bayview "without"mask (ambient) vs Bayview "with"mask site Results from biomarker response comparisons for the Bayview site "without" (ambient) vs "with" mask exposures (Test 3) are provided in Table 6. Here, increased $(p<0.05)$ levels of IL-1 $\beta$ and IL-2, as well as an increasing trend in the levels of plasma BET-1 are seen with exposures at the Bayview site "without" (ambient) mask relative to "with" mask exposures. 
Table 3 Daily average air pollutant levels on Fridays for the two study sites (Bayview and College sites)

\begin{tabular}{|c|c|c|}
\hline Pollutant & $\begin{array}{l}\text { College Site (Fridays) } \\
\text { Mean ( } 95 \% \text { CI) }\end{array}$ & $\begin{array}{l}\text { Bayview Site (Fridays) } \\
\text { Mean ( } 95 \% \text { Cl) }\end{array}$ \\
\hline CO (IQR 0.4 ppm) & $0.44(0.43,0.45)$ & $1.07(0.95,1.19)$ \\
\hline NO (IQR 6.7 ppb) & $1.52(1.44,1.60)$ & $6.93(6.61,7.24)$ \\
\hline $\mathrm{NO}_{2}$ (IQR 6.6 ppb) & $4.39(4.19,4.58)$ & $6.78(6.49,7.07)$ \\
\hline $\mathrm{NO}_{x}(\mathrm{IQR} 13.2 \mathrm{ppb})$ & $5.90(5.65,6.15)$ & $13.52(12.98,14.07)$ \\
\hline $\mathrm{O}_{3}(\mathrm{IQR} 9.2 \mathrm{ppb})$ & $32.81(32.19,33.44)$ & $29.91(29.38,30.44)$ \\
\hline $\mathrm{PM}_{2.5}\left(\mathrm{IQR} 11.0 \mu \mathrm{g} / \mathrm{m}^{3}\right)$ & $11.48(10.97,11.99)$ & $12.95(12.41,13.48)$ \\
\hline $\mathrm{SO}_{2}(\mathrm{IQR} 14.8 \mathrm{ppb})$ & $1.56(1.39,1.73)$ & $8.13(7.28,8.98)$ \\
\hline UFP (IQR 32161 particle/cm³) & $6523(6080,6966)$ & $14,830(13,604,16,057)$ \\
\hline
\end{tabular}

Individual air pollutant-related changes in biomarker levels The best fit model results for the tests of association between individual criteria air pollutant levels and plasma/saliva endpoints (Test 4) are provided in Table 7 \& Additional file 1: Table S1. In terms of cytokine levels, interquartile (IQR) increase in $\mathrm{CO}$ was associated with ca. $4.2,4.3,1.6,7.7$ and $4.6 \%$ increase $(p<0.05)$ in IL-6, IL-7, IL-8, IL-12 and IL-13 cytokines, respectively; IQR increase in $\mathrm{O}_{3}$ was associated with 47.6 and $14.3 \%$ increase in IL-2 and TNF- $\alpha(p<0.05)$ and with increasing trends $(5.3 \%)$ of IL-8; IQR increases in $\mathrm{NO}$ and $\mathrm{NO}_{\mathrm{x}}$ were associated with decreased $(p<0.05)$ IL-8 levels. In terms of endothelin

Table 4 Comparison between biomarker levels after the Bayview site ("without"mask) vs College site exposures

\begin{tabular}{|c|c|}
\hline Biomarker & $\begin{array}{l}\text { Bayview ("without" mask) vs College site } \\
\text { Ratio ( } 95 \% \mathrm{Cl})\end{array}$ \\
\hline$\overline{A 2 M}$ & $0.887(0.755,1.043)++^{a}$ \\
\hline Adiponectin & $1.184(1.013,1.385)^{* b}$ \\
\hline AGP & $0.749(0.590,0.952)^{* a}$ \\
\hline CRP & $1.410(0.887,2.240)+^{a}$ \\
\hline Haptoglobin & $0.852(0.734,0.989)^{* a}$ \\
\hline $\mathbb{I L}-1 \beta$ & $1.050(0.999,1.104)+{ }^{b}$ \\
\hline$\| \mathrm{L}-4$ & $1.317(1.021,1.699)^{* a}$ \\
\hline IL-6 & $1.143(1.002,1.305)^{* c}$ \\
\hline PF4 & $0.847(0.709,1.011)+^{a}$ \\
\hline Plasma ET-1 ${ }_{(1-21)}$ & $1.497(0.957,2.340)++^{a}$ \\
\hline Plasma ET-3 & $1.330(1.037,1.705)^{* a}$ \\
\hline Saliva BET-1 & $1.302(1.034,1.641)^{* c}$ \\
\hline Saliva $\mathrm{ET}^{-1}{ }_{(1-21)}$ & $1.167(1.031,1.320)^{* b}$ \\
\hline Saliva ET-3 & $1.114(0.979,1.267)+{ }^{b}$ \\
\hline TNF-a & $1.076(1.005,1.151)^{* c}$ \\
\hline vWF & $0.552(0.349,0.875)^{* a}$ \\
\hline
\end{tabular}

${ }^{*} p<0.05 ;+p<0.1$ (not significant, trend only)

${ }^{a}$ Covariates: Treatment period, carry over, age, sex, BMI, atmospheric pressure, temperature, relative humidity

${ }^{b}$ Covariates: Treatment period, carry over

${ }^{\mathrm{c} C o v a r i a t e s: ~ T r e a t m e n t ~ p e r i o d, ~ c a r r y ~ o v e r, ~ a g e, ~ s e x, ~ B M I ~}$ isoforms, increased $(p<0.05)$ plasma Big ET-levels were associated with IQR increases in $\mathrm{O}_{3}$, but IQR increases in $\mathrm{SO}_{2}$, and UFP were associated with increased $(p<0.05)$ plasma ET- $1_{1-21}$ levels, and similar association $(p<0.05)$ was seen with $\mathrm{PM}_{2.5}$ and saliva ET-1 $1_{1-21}$ levels. In addition, saliva ET- $1_{1-21}$ levels decreased IQR increases in CO as well as $\mathrm{O}_{3}(p<0.05)$. Acute phase protein profile results showed that adipsin, AGP, A2M, fibrinogen, haptoglobin, L-selectin and PF4 decreased $(p<0.05)$ with IQR increases in all pollutants, except for an increasing trend $(p<0.1)$ for $\mathrm{SO}_{2}$. Also, IQR increases in $\mathrm{SO}_{2}$ and $\mathrm{PM}_{2.5}$ were associated with an increasing trend in vWF levels $(p<0.1)$.

Table 5 Comparison of target biomarker levels after the Bayview site ("with" mask) vs College site exposures

\begin{tabular}{|c|c|}
\hline Biomarker & $\begin{array}{l}\text { Bayview ("with" mask) vs College site } \\
\text { Ratio }(95 \% \mathrm{Cl})\end{array}$ \\
\hline Adiponectin & $1.133(0.967,1.327)+{ }^{b}$ \\
\hline AGP & $0.744(0.584,0.949)^{* a}$ \\
\hline Haptoglobin & $0.814(0.700,0.947)^{* a}$ \\
\hline IFNY & $1.134(0.994,1.294)+{ }^{b}$ \\
\hline IL-2 & $0.782(0.640,0.956)^{* a}$ \\
\hline IL-4 & $1.229(0.950,1.590)+{ }^{a}$ \\
\hline IL-8 & $1.049(0.986,1.117)+{ }^{b}$ \\
\hline PF4 & $0.836(0.698,1.001)+{ }^{a}$ \\
\hline Plasma ET-1 ${ }_{(1-21)}$ & $1.443(0.917,2.269)+^{a}$ \\
\hline Plasma ET-3 & $1.272(0.989,1.636)+^{a}$ \\
\hline Saliva BET-1 & $1.367(1.085,1.723)^{* c}$ \\
\hline Saliva $\mathrm{ET}^{-1}{ }_{(1-21)}$ & $1.165(1.030,1.318)^{* b}$ \\
\hline Saliva ET-1 ${ }_{(1-31)}$ & $1.132(0.974,1.314)+^{c}$ \\
\hline SAP & $0.770(0.543,1.092)+{ }^{a}$ \\
\hline TNF- $a$ & $1.075(1.004,1.151)^{* c}$ \\
\hline$v W F$ & $0.622(0.390,0.991)^{* a}$ \\
\hline
\end{tabular}

${ }^{*} p<0.05 ;+p<0.1$ (not significant, trend only)

${ }^{a}$ Covariates: Treatment period, carry over, age, sex, BMI, atmospheric pressure, temperature, relative humidity

${ }^{\text {b } C o v a r i a t e s: ~ T r e a t m e n t ~ p e r i o d, ~ c a r r y ~ o v e r ~}$

${ }^{c}$ Covariates: Treatment period, carry over, age, sex, BMI 
Table 6 Comparison of target biomarker levels after the Bayview site ("without" mask) vs Bayview site ("with" mask) exposures

\begin{tabular}{llll}
\hline Comparison & $\mathrm{IL}-1 \beta$ & $\mathrm{IL}-2$ & Plasma BET-1 \\
& Ratio $(95 \% \mathrm{Cl})$ & Ratio $(95 \% \mathrm{Cl})$ & Ratio $(95 \% \mathrm{Cl})$ \\
\hline $\begin{array}{l}\text { Bayview Ambient vs } \\
\text { Bayview Mask }\end{array}$ & $1.061(1.012,1.112)^{*}$ & $1.153(1.027,1.294)^{*}$ & $1.135(0.959,1.344)+$ \\
\hline
\end{tabular}

${ }^{*} p<0.05 ;+p<0.1$ (not significant, trend only)

Note: Covariates: Treatment period, carry over, age, sex, BMI, atmospheric pressure, temperature, relative humidity

\section{Physiological measures}

Site-related changes Results on associations between physiological measures systolic/diastolic BPs, HR and exposure conditions (Test 5) from the best fit models are shown in Table 8. A decreasing trend in the systolic and diastolic BP values is seen with exposures "with" mask at the Bayview site compared to "without" mask exposures at this site, as well as when compared to College site exposures. In addition, both BP values exhibited decreasing trends after exposures at the College site compared to Bayview site exposures "without" mask. Heart rate values are increased after exposures at the Bayview site "with" mask $(p<0.05)$ relative to the Bayview site "without" mask exposures, as well as the College site exposures. Heart rate after College site exposures exhibit a decreasing trend relative to Bayview site "without" mask exposures.

Individual air pollutant-related changes The relationships between individual air pollutants and the physiological endpoints (BP and HR) from the mixed models (Test 6) are illustrated in Table 9. Decreased $(p<0.05)$ systolic $B P$ is seen with IQR increase in $\mathrm{O}_{3}$. IQR increase in UFP is associated with increased $(p<0.05)$ systolic $\mathrm{BP}$. A decrease in diastolic BP is seen with IQR increases $\mathrm{CO}, \mathrm{O}_{3}$ and $\mathrm{PM}_{2.5}$, with similar trends $(p<0.1)$ seen for $\mathrm{NO}_{2}, \mathrm{NO}_{\mathrm{x}}$ and UFP. IQR increases in $\mathrm{NO}, \mathrm{O}_{3}, \mathrm{PM}_{2.5}$ and UFP levels were associated with increased $(p<0.05)$ HR values. IQR increase in $\mathrm{NO}_{x}$ exhibited a similar trend $(p<0.1)$ in HR as well.

Biomarker levels and physiological measures Mixed model results (Test 7) for associations between plasma/ saliva markers and physiological parameters (BP, HR) showed that saliva BET-1 levels were positively associated $(p<0.05)$, while adipsin and PF4 were negatively associated $(p<0.05)$ to systolic BP levels (Table 10). Diastolic BP levels were positively associated $(p<0.05)$ with saliva BET-1 and negatively associated $(p<0.05)$ to plasma BET-1 and vWF. In addition, CRP levels were positively associated $(p<0.05)$ with heart rates, while IL- 6 and IL-12 were negatively associated $(p<0.05)$ with HR.

\section{Bioinformatic analyses}

Hierarchical clustering The heat map with hierarchical clustering visually illustrates the distinct patterns of biological responses (up-regulated and down-regulated) specific to the Bayview ("with" and "without" mask) and College site exposures (Fig. 1). Pro-inflammatory cytokines IL-1 $\beta$, IL-2, IL- 6 were upregulated after the Bayview ambient ("without" mask) exposures, compared to the other two exposure conditions. Also, at the Bayview site, IL-1 $\beta$, IL-2 and plasma BET-1 were increased for "without" mask in contrast to "with" mask exposures. Meanwhile, cytokines IL-7, IL-8, IL-13 were increased "with" mask at the Bayview site compared to "without" mask exposures. However, haptoglobin levels are decreased and anti-inflammatory IL-10 levels are increased for the "with" mask exposures compared to "without" mask exposures at the Bayview site, as well as the College site.

IPA The significant protein interaction network with the highest score was different for Bayview site "with" mask exposures compared to that of Bayview site "without" mask (Fig. 2a-b) exposures based on differentially expressed protein markers as compared separately to the College site levels. The strength of significance of association between canonical pathways for some disease outcomes and site-related exposures were higher for the Bayview site "without" mask compared to "with" mask exposures (Additional file 1: Figure S1).

\section{Discussion}

In this study, biomarkers of oxidative stress, inflammation and vascular effects were assessed in healthy humans (Table 2) exposed to air in the proximity of a steel plant site (Bayview, with and without a mask) and at a distant College site, to gain information on source-emission-related effects. Exposure to elevated air pollution levels is linked to adverse health effects including cardiac remodelling [44]. Local inflammatory response in the lung is one of the accepted consequences of air particle exposures and is considered to lead to systemic vascular oxidative stress and inflammation that result in adverse cardiac remodelling. We thus assessed the levels of plasma/saliva target markers relevant to these biological processes. Only the subjects 
Table 7 Relative change in target biomarker levels associated with IQR changes in air pollutant levels

\begin{tabular}{|c|c|c|}
\hline Pollutant & Biomarker & Ratio $(95 \% \mathrm{Cl})$ \\
\hline \multirow[t]{10}{*}{$\mathrm{CO}$} & IL-12 & $1.077(1.018,1.139)^{*}$ \\
\hline & IL-13 & $1.046(1.009,1.086)^{*}$ \\
\hline & IL-5 & $1.022(0.998,1.047)+$ \\
\hline & IL-6 & $1.042(1.009,1.077)^{*}$ \\
\hline & IL-7 & $1.043(1.007,1.080)^{*}$ \\
\hline & IL-8 & $1.016(1.001,1.032)^{*}$ \\
\hline & L Selectin & $0.966(0.934,1.000)^{*}$ \\
\hline & ET 1-21 (saliva) & $0.966(0.933,1.000)^{*}$ \\
\hline & ET 1-31 (saliva) & $0.962(0.920,1.007)+$ \\
\hline & ET 3 (saliva) & $1.011(0.975,1.047)+$ \\
\hline \multirow[t]{3}{*}{ NO } & GMCSF & $0.910(0.818,1.012)+$ \\
\hline & IL-4 & $0.859(0.718,1.027)+$ \\
\hline & IL-8 & $0.906(0.845,0.972)^{*}$ \\
\hline $\mathrm{NO}_{2}$ & ET 1-21 (saliva) & $1.090(0.904,1.314)+$ \\
\hline $\mathrm{NO}$ & IL-8 & $0.915(0.847,0.989)^{*}$ \\
\hline \multirow[t]{10}{*}{$\mathrm{O}_{3}$} & Adipsin & $0.669(0.433,1.034)+$ \\
\hline & GMCSF & $1.170(0.979,1.398)+$ \\
\hline & $\mathrm{IL}-2$ & $1.476(1.120,1.945)^{*}$ \\
\hline & L Selectin & $0.794(0.630,1.000)+$ \\
\hline & Big ET-1 (plasma) & $1.417(1.024,1.962)^{*}$ \\
\hline & Big ET-1 (saliva) & $0.616(0.363,1.046)+$ \\
\hline & ET 1-21 (saliva) & $0.776(0.609,0.988)^{*}$ \\
\hline & SAP & $0.672(0.445,1.013)+$ \\
\hline & TNF-a & $1.143(1.006,1.299)^{*}$ \\
\hline & vWF & $0.562(0.328,0.963)^{*}$ \\
\hline \multirow[t]{4}{*}{$\mathrm{SO}_{2}$} & Haptoglobin & $1.080(0.988,1.182)+$ \\
\hline & PF4 & $0.914(0.829,1.007)+$ \\
\hline & ET 1-21 (plasma) & $1.401(1.056,1.858)^{*}$ \\
\hline & VWF & $1.265(0.953,1.679)+$ \\
\hline \multirow[t]{8}{*}{ UFP } & $\mathrm{A} 2 \mathrm{M}$ & $0.543(0.348,0.848)^{*}$ \\
\hline & Adipsin & $0.244(0.095,0.627)^{*}$ \\
\hline & AGP & $0.362(0.209,0.626)^{*}$ \\
\hline & Fibrinogen & $0.504(0.309,0.823)^{*}$ \\
\hline & Haptoglobin & $0.548(0.359,0.837)^{*}$ \\
\hline & L Selectin & $0.684(0.495,0.947)^{*}$ \\
\hline & PF4 & $0.464(0.287,0.750)^{*}$ \\
\hline & ET 1-21 (plasma) & $4.405(1.143,16.973)^{*}$ \\
\hline \multirow[t]{4}{*}{$\mathrm{PM}_{2.5}$} & $\mathrm{IL}-4$ & $0.837(0.700,1.000)+$ \\
\hline & ET 1-21 (saliva) & $1.166(1.001,1.344)^{*}$ \\
\hline & ET 1-31 (saliva) & $1.195(0.998,1.430)+$ \\
\hline & vWF & $1.373(0.985,1.912)+$ \\
\hline
\end{tabular}

${ }^{*} p<0.05 ;+p<0.1$ (not significant, trend only)

Covariates: Treatment period, carry over, Age, sex, BMI, atmospheric pressure, temperature and relative humidity who consented to blood draws on Fridays of the weeks during this exposure period were included in this work.

The criteria air pollutant levels on Fridays (daily average) varied between exposure sites, especially with increases in $\mathrm{SO}_{2}$, UFP, $\mathrm{CO}, \mathrm{NO}$ and $\mathrm{NO}_{\mathrm{x}}$ at the Bayview site compared to the College site (Table 3), these findings were in line with the weekly average results for these neighborhoods [43]. Steel plant activities are typically expected to generate emissions of $\mathrm{CO}, \mathrm{SO}_{2}, \mathrm{NO}_{\mathrm{x}}$ and particles that can vary with operational conditions [66]. Sioutas et al., 2005 [61] reported that long range transport is usually not a major source of UFP unlike $\mathrm{PM}_{2.5}$, since UFP has a short lifetime. It is therefore plausible that increased UFP levels at the Bayview site could be attributed to the local emitters at this site. In terms of UFPs, this was associated with relatively large variation. However, we found that variations in UFPs are statistically significantly associated with all eight biomarkers. If the large variation was due to some random errors we would not find so many significant associations. It is unlikely that so many significant associations happen due to random chance alone.

Our general analysis of target biomarker data showed a positive correlation $(p<0.05)$ between saliva and plasma BET-1 levels consistent with our previous work [21]. The lipid oxidation marker 8-isoprostane (8-ISOP) in plasma, a marker of oxidative stress was positively related to plasma BET-1 $(p=0.05)$, but was negatively associated $(p<0.05)$ with ET-1 $1_{1-21}$, suggesting that oxidative stress may play a role in mediating BET-1, ET-1 responses [38]. BET-1 is cleaved by the endothelin converting enzyme (ECE) to form a mature peptide ET-1, and thus ECE levels can influence the circulating BET-1 and ET-1 levels [30]. Furthermore, our observation on the relationship between plasma BET-1 and PF4 is in line with previous findings on endothelin-induced stimulation of platelet activating factors [48, 49]. Positive associations between AGP, fibrinogen, SAP and haptoglobin as well as with the pro-inflammatory cytokines such as IL-8, TNF- $\alpha$, IFN- $\gamma$ in these subjects are typical immune responses. The strength of the correlations observed in this study may be weak due to the smaller sample size and because the study participants were healthy subjects.

We focussed on significant $(p<0.05)$ mixed effects model results, since we are aware that false associations due to multiple comparisons may occur during statistical analyses on a relatively large dataset. Yet, due to the exploratory nature of this work, we also show trends in some consistent, mechanistically meaningful target biomarkers (did not reach significance, $p<0.1$ ) that are known to respond with air pollutant exposures, and the directionality of these markers can be useful in collective biomarker pattern-based mechanistic verification. 
Table 8 Change in physiological endpoints by exposure

\begin{tabular}{llll}
\hline Site Comparison & \multicolumn{2}{l}{ Physiological endpoint } & \\
\cline { 2 - 4 } & $\begin{array}{l}\text { Systolic BP }(\mathrm{mmHg}) \\
\text { Change }(95 \% \mathrm{Cl})\end{array}$ & $\begin{array}{l}\text { Diastolic }(\mathrm{mmHg}) \\
\text { Change }(95 \% \mathrm{Cl})\end{array}$ & $\begin{array}{l}\text { Heart Rate }(\mathrm{bpm}) \\
\text { Change }(95 \% \mathrm{Cl})\end{array}$ \\
\hline Bayview "with" mask vs College site & $-0.7439(-3.4666,1.9789)$ & $-0.5652(-2.7252,1.5947)$ & $3.5312(1.1294,5.9330)^{*}$ \\
Bayview "with" mask vs Bayview "without" mask & $-1.2172(-3.8714,1.4370)$ & $-0.6673(-2.7715,1.4368)$ & $2.3532(0.0150,4.6913)^{*}$ \\
College site vs Bayview "without" mask & $-0.4733(-3.1738,2.2272)$ & $-0.1021(-2.2438,2.0396)$ & $-1.1780(-3.5589,1.2029)^{*}$ \\
\hline * $p<0.05$ & & &
\end{tabular}

Association of study site exposures to biomarker levels exhibited increased $(p<0.05)$ pro-inflammatory cytokines, vasoactive endothelins, and an increasing trend in a known marker of inflammation CRP [14, 32] (Table 4) after Bayview site "without"mask exposures compared to College site exposures, suggesting activation of proinflammatory pathways and alteration in endothelin homeostasis at the Bayview site. Yet, decreased AGP, haptoglobin and vWF levels and increased adiponectin (that is secreted by the adipose tissue) levels, after Bayview site exposures compared to College site exposures suggest probably a transient disturbance in acute phase protein homeostasis. Because this is a short term exposure study and is conducted with healthy subjects, active compensatory feedback mechanisms can be operative.

Although the Bayview site "with mask" exposures were associated with some significantly $(p<0.05)$ altered some inflammatory and vascular function-related biomarker levels as with "without mask" exposures at this site, compared to College site exposures (Table 5), "with mask" exposures only affected less number of biomarkers contributing to the above noted biological processes, implying selective and reduced effects. It was also interesting to note increased $(p<0.05)$ plasma IL-1 $\beta$ and IL-2 levels and an increasing trend $(p<0.1)$ in plasma BET-1 levels after Bayview site "without" mask exposures compared to "with" mask exposures (Table 6) implying only some modifications to biomarker responses even after filtration of many criteria pollutants by the mask, at this site. Coke oven emissions from steel mills are known to contribute to VOC, SVOCs (e.g. PAHs, benzene, dioxins, furans) in their vicinity, and these pollutants have been associated with inflammatory and cardiovascular effects [13]. The main focus of this study was criteria pollutants and the mask filtered most of them except for $C O$ and UFP $<0.3 \mu \mathrm{m}$ size, and we assume that the VOC and SVOCs were filtered by the mask.

The mixed effects model results on the associations between single air pollutants and biomarkers identified individual pollutant-specific effects (Table 7 \& Additional file 1: Table S1). For instance, IQR increases in $\mathrm{O}_{3}$ and $\mathrm{CO}$ levels were associated with increased proinflammatory cytokines suggesting pollutant-specific activation of pro-inflammatory mechanisms [46]. However, IQR increases in $\mathrm{CO}$ and $\mathrm{O}_{3}$ levels were associated with decreased acute phase proteins L-Selectin and vWF, respectively. Similar association between $\mathrm{O}_{3}$ and vWF has been reported before [56]. Meanwhile, IQR increases in $\mathrm{NO}$ and NOx were associated with decreased IL-8 levels in these subjects. In terms of vascular function-related effects, IQR increases in the gaseous pollutants $\mathrm{SO}_{2}, \mathrm{O}_{3}$ and $\mathrm{CO}$ were associated with (Table 7) pollutant-specific endothelin responses. Plasma and also saliva ET- $1_{1-21}$ levels have been implicated in cardiovascular diseases $[11,15]$. Interestingly, the particulate air pollutants UFP and $\mathrm{PM}_{2.5}$ fractions were also associated with different

Table 9 IQR changes in air pollutants and associated changes in physiological endpoints

\begin{tabular}{llll}
\hline Pollutant & \multicolumn{2}{l}{$\begin{array}{l}\text { Physiological endpoints } \\
\text { Change }(95 \% \mathrm{Cl})\end{array}$} & Heart Rate \\
\cline { 2 - 4 } & Systolic BP & Diastolic BP & $0.13(-0.11,0.36)$ \\
$\mathrm{CO}(\mathrm{ppm})$ & $-0.07(-0.34,0.20)$ & $-0.22(-0.45,-0.002)^{*}$ & $1.75(0.47,3.03)^{*}$ \\
$\mathrm{NO}(\mathrm{ppb})$ & $0.46(-0.87,1.79)$ & $0.62(-0.48,1.72)$ & $0.60(-0.84,2.03)$ \\
$\mathrm{NO}_{2}(\mathrm{ppb})$ & $-0.74(-2.73,1.24)$ & $-1.64(-3.31,0.030)+$ & $1.89(-0.002,3.78)+$ \\
$\mathrm{NO}_{x}(\mathrm{ppb})$ & $0.31(-1.64,2.25)$ & $-1.64(-3.54,0.25)+$ & $1.62(0.49,2.75)^{*}$ \\
$\mathrm{O}_{3}(\mathrm{ppb})$ & $-1.48(-2.76,-0.20)^{*}$ & $-1.82(-2.85,-0.78)^{*}$ & $1.52(0.35,2.7)^{*}$ \\
$\mathrm{PM}_{2.5}\left(\mathrm{ug} / \mathrm{m}^{3}\right)$ & $-0.97)(-2.31,0.38)$ & $-1.97(-3.04,-0.89)^{*}$ & $0.22(-0.53,0.98)$ \\
$\mathrm{SO}_{2}(\mathrm{ppb})$ & $-0.15(-0.70,1.01)$ & $-0.26(-0.96,0.45)$ & $1.35(0.29,2.42)^{*}$ \\
UFP $\left(\mathrm{particle} / \mathrm{cm}^{3}\right)$ & $6.25(2.79,9.71)^{*}$ & $-4.67(-9.56,0.22)+$ & 1
\end{tabular}

${ }^{*} p<0.05 ;+p<0.1$ (not significant, trend only)

Covariates: Carry over, age, sex and BMI, sequential order of treatments 
Table 10 Change in physiological endpoints associated with IQR changes in target biomarkers

\begin{tabular}{llll}
\hline Biomarker & \multicolumn{2}{l}{$\begin{array}{l}\text { Physiological Parameters } \\
\text { Change }(95 \% \mathrm{Cl})\end{array}$} & Heart Rate $(\mathrm{bpm})$ \\
\cline { 2 - 4 } & Systolic BP $(\mathrm{mmHg})$ & $0.38(-0.81,1.04)^{\mathrm{a}}$ & $-0.06(-1.62,1.51)^{\mathrm{a}}$ \\
\hline Adipsin & $-1.94(-3.62,-0.26)^{* a}$ & $0.24(-0.27,0.76)^{\mathrm{a}}$ & $1.13(0.56,1.69)^{* \mathrm{~b}}$ \\
CRP & $0.40(-0.28,1.08)^{\mathrm{a}}$ & $-0.15(-0.77,0.47)^{\mathrm{a}}$ & $-0.61(-1.33,0.10)+^{\mathrm{a}}$ \\
IL-10 & $-0.01(-0.85,0.82)^{\mathrm{a}}$ & $-0.05(-0.20,0.10)^{\mathrm{a}}$ & $-0.25(-0.42,-0.08)^{* a}$ \\
IL-12 & $-0.07(-0.27,0.14)^{\mathrm{a}}$ & $-0.09(-0.09,0.73)^{\mathrm{a}}$ & $-1.09(-2.01,-0.17)^{* a}$ \\
IL-6 & $0.08(-1.00,1.15)^{\mathrm{a}}$ & $-0.20(-0.88,0.47)^{\mathrm{a}}$ & $-0.68(-1.45,0.10)+^{\mathrm{a}}$ \\
IL-7 & $-0.14(-1.05,0.76)^{\mathrm{a}}$ & $0.19(-0.87,1.26)^{\mathrm{a}}$ & $0.03(-1.17,1.24)^{\mathrm{a}}$ \\
PF4 & $-1.57(-2.95,-0.19)^{* a}$ & $-1.22(-2.65,0.20)^{* \mathrm{c}}$ & $-0.44(-2.17,1.30)^{\mathrm{a}}$ \\
Plasma BET-1 & $1.41(-0.59,3.41)^{\mathrm{a}}$ & $1.11(0.08,2.14)^{* \mathrm{a}}$ & $-0.02(-1.21,1.16)^{\mathrm{a}}$ \\
Saliva BET-1 & $1.82(0.64,3.00)^{* \mathrm{a}}$ & $0.66(-0.94,2.25)^{\mathrm{a}}$ & $-1.01(-2.81,0.80)^{\mathrm{a}}$ \\
Saliva ET-1(1-21) & $1.78(-0.25,3.80)+^{\mathrm{a}}$ & $0.77(0.08,1.45)^{* \mathrm{a}}$ & $-0.39(-1.22,0.43)+^{\mathrm{a}}$ \\
VWF & $-0.35(-1.25,0.55)^{\mathrm{a}}$ & & \\
\hline
\end{tabular}

${ }^{*} p<0.05 ;+p<0.1$ (not significant, trend only)

${ }^{a}$ Covariates: Treatment period, and carry over

${ }^{\mathrm{b} C}$ Covariates:Treatment period, carry over, age, sex and BMI

'Covariates: Treatment period, carry over, age, sex and BMI, atmospheric pressure, temperature, and relative humidity

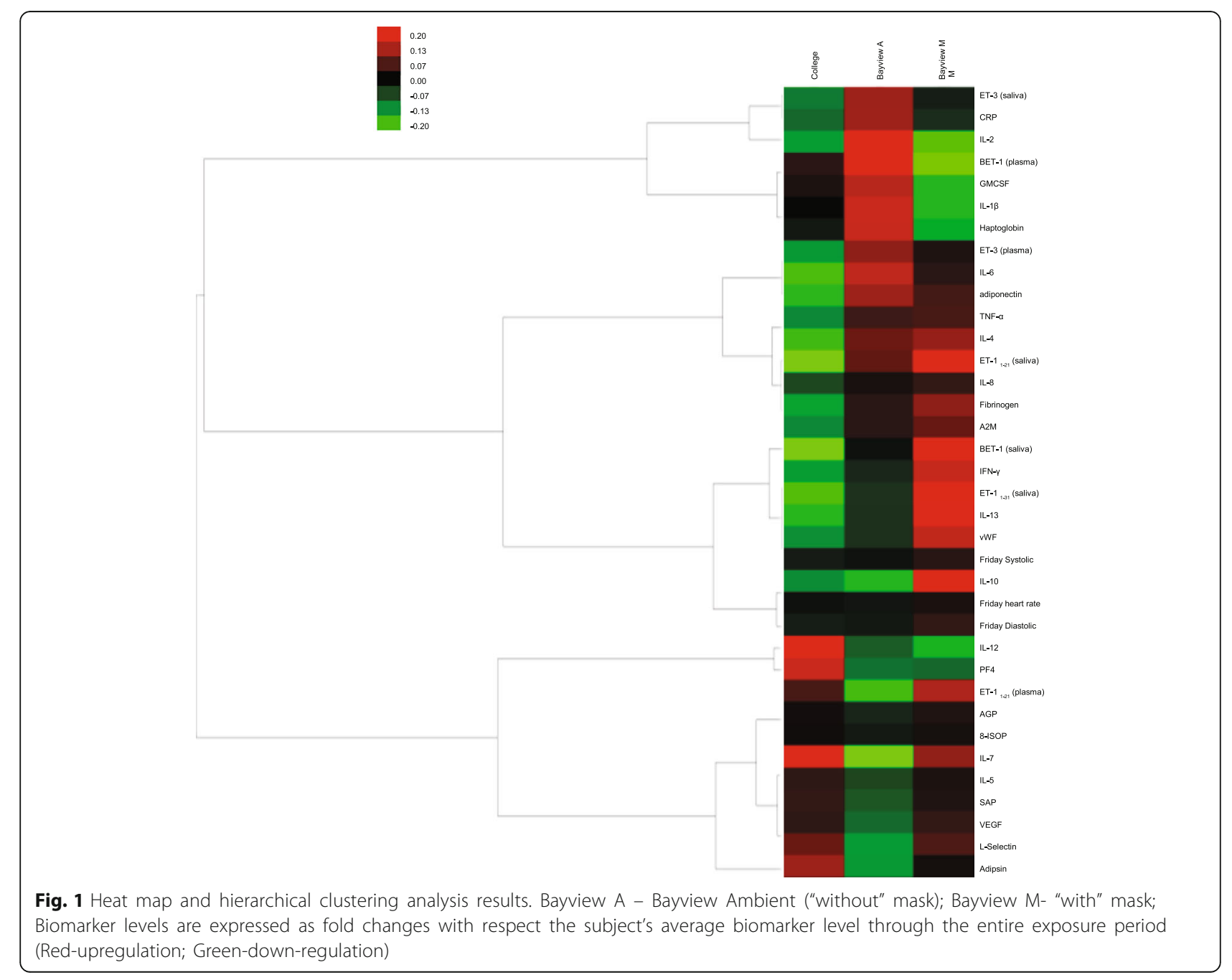




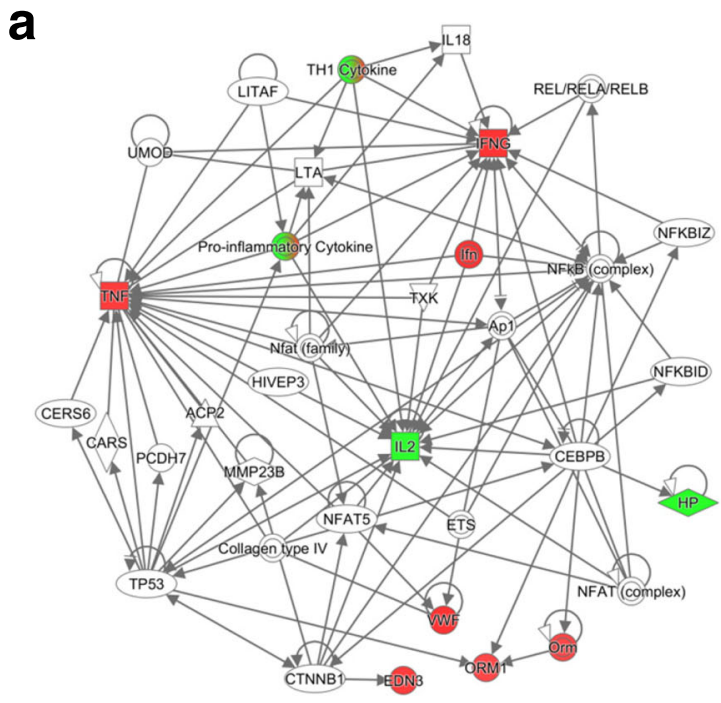

b

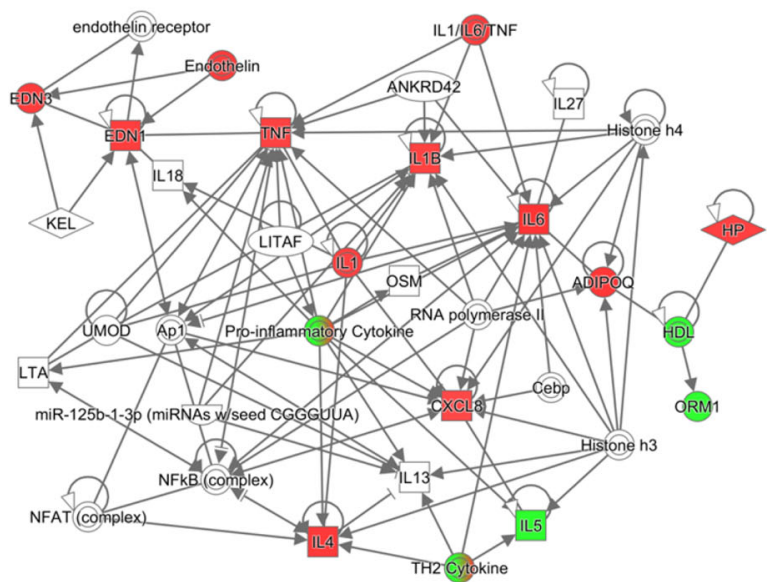

Fig. 2 Protein networks from IPA analyses. Biomarker levels at the Bayview site are expressed as fold changes with respect to the College site levels. a Network 1 ("with" mask) b Network 2 ("without" mask). (Red- upregulation; Green- down-regulation)

plasma/saliva marker profiles (Table 7 \& Additional file 1: Table S1). IQR increase in UFP was associated with increased plasma ET- $1_{1-21}$ and decreased acute phase protein responses, while IQR increases in $\mathrm{PM}_{2.5}$ levels are associated with increased saliva ET-1 $1_{1-21}$ levels, demonstrating PM size-related differences in biomarker profiles. Similar PM-related biomarker responses have been observed previously $[23,50,63,69]$. It was interesting to note that increasing trend $(p<0.1)$ in vWF levels were observed with IQR increases in $\mathrm{SO}_{2}$ and $\mathrm{PM}_{2.5}$ levels.(Table 7) Increased plasma vWF, a multifunctional glycoprotein is known to be associated with thrombosis [73]. These individual pollutant-related changes in biomarker responses were assessed to get some notion of individual pollutant's contribution to the overall effects, from exposure to three types of air pollutant mixtures (Bayview site "with" and "without" mask, and College site exposures). However, individual air pollutant-specific biomarker responses seemed to only explain very few site-related effects (e.g. IL-6, saliva ET-1 $1-21$ ), and the remainder of 
the site-related responses appeared to be influenced by inter-pollutant interactions based on the nature of the air pollutant mixture [38]. As indicated before, the mask used in this study filtered most criteria air pollutants except for $\mathrm{CO}$ and $<0.3 \mu \mathrm{m}$ PM (e.g UFP) at the Bayview site. The increased plasma IL-8, ET-1 $1_{1-21}$, adiponectin and decreased haptoglobin responses associated "with" mask exposures at this site appeared to be typical responses for IQR increases in CO and UFP (Tables 5, 7) and perhaps associated inter-pollutant interactions including non-criteria pollutants that may have filtered through the mask. Furthermore, the mask appeared to dampen or favour some mechanistic pathways. This observation is similar to a previous report by Karthikeyan et al., 2013 [29] where the use of diesel particle filter increased some biological responses even though it filtered particulate matter effectively, and thus the observed effects were attributed to increased $\mathrm{NO}_{2}$ levels, instead. On the other hand, the use of mask at the Bayview site inadvertently served as a tool for deconstruction of the complex air pollution mixture at this site, and offered an opportunity to assess the effects of select components of the exposure matrix, with insight into inter-pollutant interactions on these simple pollutant mixtures.

In terms of site-related changes on physiological measures (BP and HR), both systolic and diastolic BP values (Fridays) were relatively decreased (not significant) after Bayview site "with" mask exposures compared to the other two exposures (Table 8). Nevertheless, Bayview site "with" mask exposures were associated with relatively increased heart rate compared to Bayview site "without" mask and College site exposures. Also, heart rate was lower after College site exposures relative to Bayview site "without" mask exposures. These findings are consistent with previous reports [43]. Interestingly, the use of mask is shown to improve air pollution exposure-related physiological outcomes [39]. Associations between individual air pollutants and physiological measures, indicated increased $(p<0.05)$ systolic blood pressure (SysBP) with UFP, but not with $\mathrm{PM}_{2.5}$ (Table 9). Similar finding was reported by Pieters et al., [50]. Increased ozone and CO levels were associated with decreased BP values. Interestingly exposure to $\mathrm{CO}$ is associated with low BP (https://medlineplus.gov/ency/article/002804.htm). Also, IQR increases in $\mathrm{PM}_{2.5}$ and UFP were associated with increased heart rate values, and similar relationships were seen with $\mathrm{O}_{3}, \mathrm{NO}$ and $\mathrm{NO}_{\mathrm{x}}$. Increased systolic and diastolic BP values were associated $(p<0.05)$ with increased saliva BET-1 levels in this study (Table 10). This is in line with previous findings in animal models and in humans $[4,20,75,76]$. In addition, heart rate was positively associated $(p<0.05)$ with plasma CRP (Table 9), consistent with a previous report by Pope et al., 2004 [53]. In addition, we have previously reported on the impact of increased air pollution levels at the Bayview site on autonomic control of the heart [60]. CRP is associated with cardiovascular disease mechanisms [57]. Overall, these observations imply some perturbations in cardiovascular function at the Bayview site. Nevertheless, increased anti-inflammatory adiponectin levels [27], and decreased haptoglobin the major hemoglobin binding protein associated with Bayview site exposures, support activation of some compensatory mechanisms [31, 40, 41, 47].

Overall, the mixed model results suggest that relatively high levels of air pollutants at the Bayview site may have contributed to elevated levels of some pro-inflammatory markers and endothelins as well as some acute phase protein changes. Even though the use of mask removed many criteria pollutants, CO and UFP fractions filtered through this mask along with any escaped VOCs may have contributed to the relatively decreasing trends in $\mathrm{BP}$ and increasing heart rate compared to other exposures. Although, CO X UFP interaction can explain the observed results, since $\mathrm{CO}$ exposure is associated with lowering of $\mathrm{BP}$ through cGMP pathway [68], it could be considered as the main contributor to the observed BP effect. This is consistent with a positive association (not significant) seen between CO and VEGF, in this work (Additional file 1: Table S1). Meanwhile, in this work UFP is associated with increased plasma endothelin (ET-1) (Table 7) and increasing trend (not significant) in CRP (Additional file 1: Table S1), and ET-1 is known to induce CRP via MAPK signaling in vascular smooth muscle cells and effect vasopressor responses [77]. These results are consistent with the positive associations seen between UFP and heart rate, as well as CRP and heart rate. These findings reveal that the simplification of the air pollutant mix by the use of mask can provide relatively clear information on pollutant-specific molecular changes that can potentially lead to observed physiological effects.

Alternatively, heat map and hierarchical clustering results on normalized biomarker data (to remove the inter-subject variability) also revealed that Bayview and College site exposures elicited distinct inflammatory and endothelinergic responses (Fig. 1) as with the mixed model results. For instance, pro-inflammatory cytokines IL-1 $\beta$, IL-2, IL- 6 and plasma BET- 1 were seen to be upregulated after the Bayview ambient ("without" mask) exposures, compared to the other two exposure conditions and this is consistent with the statistical model results (Table 7). However, decreased haptoglobin levels and increased anti-inflammatory IL-10 levels for the "with" mask exposures compared to "without" mask exposures at the Bayview site, as well as the 
College site, support the concept of active compensatory mechanisms. (Fig. 1).

Protein interaction networks obtained by conducting Ingenuity Pathway Analyses (IPA) on normalized multiple protein biomarker information (included significant changes) provided mechanistic information [25]. The highest scoring protein networks A and B with highest scores corresponding to "with" and "without" mask exposures at the Bayview site, respectively (Fig. 2a-b) exhibited NF-kB and proinflammatory cytokine nodes in both networks suggesting activation of inflammatory pathways after both these exposures. Nevertheless, the networks related to "with" and "without" mask exposures at the Bayview site appear to be somewhat different (Fig. 2a-b) and suggest Th1 (cell-mediated immunity and inflammation) and Th2 (allergy type inflammation)-like inflammatory responses, respectively [64]. The two types of helper T cells (Th1, Th2) produce cytokines characteristic of the corresponding inflammatory responses. Furthermore, network B corresponding to the Bayview site "without" mask exposures with increased IL-1 $\beta$, IL-4, IL-6 and ET-1 may suggest some vascular immune responses. Pro-inflammatory changes such as increased IL-6 and TNF- $\alpha$ levels (Tables 5, 5, 6, 7, 8) are known to trigger acute phase protein responses and increase endothelins exhibiting signs similar to endothelial dysfunction $[19,22$, 24, 27, 71]. Vascular wall cells, macrophages and Th2 cells can contribute to increased IL- $1 \beta$, IL- 4 , IL- 6 and ET- 1 levels. IL-4 is known to increase IL-6 levels and impact on vascular endothelial cell barrier function [62]. IL-1 $\beta$ is known to induce prepro ET-1 gene by various mechanisms [24]. Moreover, UFP and $\mathrm{SO}_{2}$ are shown to mediate NFkB-signalling pathway-related inflammatory conditions $[12,58]$, while exposure to particulate matter is known to trigger Th2 type immune responses and negatively impact on pulmonary vasculature [18]. We have reported on reduced pulmonary function in subjects after exposure at the Bayview site [10], and there are recent findings suggesting airway inflammation (Kauri et al. unpublished results) associated with exposures at this site. Also, these protein interaction networks are consistent with the molecular mechanisms proposed for air pollution exposure-related effects [44]. The canonical pathway analyses by IPA identified various disease functions including cell growth and proliferation, cell-cell signalling, immune cell trafficking, inflammatory response and cardiovascular disease, for Bayview site exposures (Additional file 1: Figure S1).

Despite the strengths of this work, there were some limitations in this study. For instance, masks were used only at the source emission site, the site central to this study and not at the college site, due to budget, timeline and resource constraints-driven 3-type of exposure design. Also, the subjects in this study had to raise the hood of the mask during eating and drinking for very short periods of time, for snacks and lunch. However, the hood was up for a brief period during food intake only, and there still was a flow of cool, clean air over them. Also, the hood was up during the lung function tests [10], yet this was conducted for all subjects for the same time period in a closed cooler relatively clean air system (In a trailer at the Bayview site, and inside the building at the college site). Throughout their participation in the study (including the washout period), participants were asked to refrain from spending time in locations they would be exposed to second hand smoke and from working at locations with increased air pollution. Nevertheless, the reported results should be considered as relative responses. Besides, this is a short-term exposure study with a focus only on healthy subjects. Furthermore, air pollutants other than the criteria pollutants were not measured in this study, as well as the air pollutants under the mask were not measured in this work.

In essence, the multiple biomarker analysis along with the use of mask in this work is a novel approach for the assessment of air pollution-related health effects. Exposure to relatively higher air pollutant levels in the Bayview neighborhood may mediate molecular mechanisms relevant to inflammatory and vascular function-related pathways. Activation of some compensatory mechanisms noticed in these healthy subjects may have played a protective role thus resulting in only subtle physiological changes. Single air pollutant-specific biomarker responses in combination with exposure type-related differences assisted in gaining insight into inter-pollutant interactions. Furthermore, the unique approach of use of mask along with multiple biomarker response information in different biological compartments permitted insight into source emission-associated mechanistic changes related to observed physiological outcomes. Thus, these findings contribute to the advancement of source emission-related risk assessment efforts.

\section{Conclusions}

Our findings from multiple biomarker analyses reveal that elevated air pollutant levels at the steel mill site can contribute to perturbations in inflammatory and vascular mechanisms, and perhaps may explain the subtle physiological changes seen in this study and in previous reports. The use of mask can permit experimental deconstruction of complex air pollution mixtures thus simplifying the exposure matrix to gain insight on target pollutant-specific effects as well as inter-pollutant interactions. This work warrants the use of high content biomarker analyses (e.g. proteomic, metabolomic) in combination with the use of mask in future air pollution exposure studies, to advance the understanding on source emission-related adverse outcome pathways. 


\section{Additional file}

Additional file 1: Figure S1. Canonical pathways identified by IPA analysis using Fisher's exact test on protein marker changes. BM (Bayview "with" mask exposures) vs C (College site exposures) - Dark Blue; BA (Bayview ambient, "without" mask exposures) vs C (College site exposures) - Pale Blue. (DOCX 100 kb)

\section{Abbreviations}

8-ISOP: 8-isoprostane; A2M: $a_{2}$-macroglobulin; AGP: a-acid glycoprotein; BMl: Body mass index; BP: Blood pressure; CRP: C-reactive protein; ECE: Endothelin converting enzyme; ETs: Endothelins; GMCSF: Granulocyte macrophage colony-stimulating factor; HR: Heart rate; IFN- $\gamma$ : Interferon gamma; IL: Interleukins; IPA: Ingenuity Pathway Analysis; IQR: Interquartile range; PF4: Platelet factor; REML: Restricted Maximum Likelihood; SAP: Serum amyloid protein; TNF-a: Tumour necrosis factor; UFP: Ultrafine particles; VWF: VonWillebrand Factor

\section{Acknowledgements}

The authors would like to acknowledge Ildiko Horvath (Project Site Coordinator), Stephanie Blaney (Assistant Project Site Coordinator), the NORDIK Institute, Algoma University, Sault Ste. Marie, Canada; Lorie Bottos (City Solicitor), City of Sault Ste. Marie; Rod Stewart (District Supervisor) and Blair McLaughlin (Senior Environmental Officer), Ontario Ministry of the Environment; David Trowbridge (Professor), Sault College; Dr. Anne Lee, the GroupHealth Centre, Sault Ste. Marie; Ryan Kulka and Liu Sun, Exposure Assessment Section, Health Canada; Marc Smith-Doiron, Population Studies Division, Health Canada; Sheryl Bartlett, Population Studies Division, Health Canada. We would also like to thank the internal reviewers Drs Bhaja Krushna Padhi and Dharani Das, EHSRB, Health Canada, for their valuable comments.

\section{Funding}

This work was funded by the Clean Air Regulatory Agenda at Health Canada, Government of Canada.

\section{Availability of data and materials}

Participants did not consent to third party access to their data or samples.

\section{Authors' contributions}

PK contributed to the study design and deployment and made a substantial contribution to the analysis and interpretation of data, drafted and revised the manuscript. RV contributed to project development, experimental design and manuscript revisions. EB assisted in study deployment and performed biomarker analysis, assisted in data analysis and manuscript preparation. $A B$ performed biomarker analysis and assisted in manuscript preparation. JG contributed to study coordination, deployment and manuscript preparation. AF assisted in study deployment and performed biomarker analysis. OB contributed statistical analysis. SC contributed in statistical analysis. EMT contributed to project development and experimental design, and to manuscript revision. RS contributed to study coordination and to manuscript revision. LMK contributed to study coordination, and manuscript revision. MM contributed to study design, statistical analysis and data evaluation. LL contributed to study design and manuscript revision. RD contributed to the experimental design and manuscript revision. All authors read and approved the final manuscript.

\section{Ethics approval and consent to participate}

The study was reviewed approved by the Health Canada Research Ethics Board (reference number 2009-0044) and the ethics board at Algoma University. Consent to participate was obtained from all subjects. Each participant completed an ethics board approved informed consent process, and were advised that they could refuse to participate in individual tests, or withdraw from the study at any time, without penalty. Please see previous papers from cohort study by Dales et al., 2013 [10], Lui et al., 2014 [43], Cakmak, et al., 2014 [6] and Shutt et al., 2017 [60].

\section{Consent for publication}

Informed consent was sought from all study participants using the Research Ethics Board approved consent process, including informed consent for publication of aggregated results in peer reviewed publications.

\section{Competing interests}

The authors declare that they have no competing interests.

\section{Publisher's Note}

Springer Nature remains neutral with regard to jurisdictional claims in published maps and institutional affiliations.

\section{Author details}

${ }^{1}$ Environmental Health Science and Research Bureau, Environmental and Radiation Health Sciences Directorate, HECSB, Health Canada, Ottawa, ON, Canada. ${ }^{2}$ Interdisciplinary School of Health Sciences, Faculty of Health Sciences, University of Ottawa, Ottawa, ON, Canada. ${ }^{3}$ Department of Biochemistry, Microbiology and Immunology, Faculty of Medicine, University of Ottawa, Ottawa, ON, Canada.

Received: 13 December 2017 Accepted: 25 July 2018

Published online: 10 August 2018

\section{References}

1. Akhtar US, Rastogi N, McWhinney RD, Urch B, Chowb C, Evans GJ, et al. The combined effects of physicochemical properties of size-fractionated ambient particulate matter on in vitro toxicity in human A549 lung epithelial cells. Toxicol Rep. 2014;1:145-56.

2. Bielecki A, Saravanabhavan G, Blais E, Vincent R, Kumarathasan P. Efficient sample preparation method for high-throughput analysis of 15(S)-8-isoPGF2a in plasma and urine by enzyme immunoassay. J Anal Toxicol. 2012 36:595-600.

3. Bouthillier L, Vincent R, Goegan P, Adamson IYR, Bjarnason S, Guenette J, et al. Acute effects of inhaled urban particles and ozone: lung morphology, macrophage activity, and plasma Endothelin-1. Am J Pathology. 1998;153(6): 1873-84.

4. Brook RD, Brook JR, Urch B, Vincent R, Rajagopalan S, Silverman F. Inhalation of fine particulate air pollution and ozone causes acute arterial vasoconstriction in healthy adults. Circulation. 2002;105(13):1534-6.

5. Burnett RT, Brook J, Dann T, Delocla C, Philips O, Cakmak S, et al. Association between particulate-and gas-phase components of urban air pollution and daily mortality in eight Canadian cities. Inhal Toxicol. 2000; 12(4):15-39.

6. Cakmak S, Dales R, Kauri LM, Mahmud M, Van Ryswyk K, Vanos J, et al. Metal composition of fine particulate air pollution and acute changes in cardiorespiratory physiology. Environ Pollut. 2014;189:208-14.

7. Calderón-Garcidueñas L, Mora-Tiscareño A, Fordham LA, Valencia-Salazar G, Chung CJ, Rodriguez-Alcaraz A, et al. Respiratory damage in children exposed to urban pollution. Pediatr Pulmonol. 2003:36(2):148-61.

8. Calderón-Garcidueñas L, Kavanaugh M, Block M, D'Angiulli A, DelgadoChávez R, Torres-Jardón R, et al. Neuroinflammation, hyperphosphorylated tau, diffuse amyloid plaques, and down-regulation of the cellular prion protein in air pollution exposed children and young adults. J Alzheimers Dis. 2012;28(1):93-107

9. Carll AP, Haykal-Coates N, Winsett DW, Hazari MS, Ledbetter AD, Richards $J$, et al. Cardiomyopathy confers susceptibility to particulate matterinduced oxidative stress, vagal dominance, arrhythmia and pulmonary inflammation in heart failure-prone rats. Inhal Toxicol. 2015;27(2):100-12.

10. Dales R, Kauri LM, Cakmak S, Mahmud M, Weichenthal SA, Van Ryswyk K, et al. Acute changes in lung function associated with proximity to a steel plant: a randomized study. Environ Int. 2013;55:15-9.

11. Denver R, Tzanidis A, Martin P, Krum H. Salivary endothelin concentrations in the assessment of chronic heart failure. Lancet. 2000;355(9202):468-9.

12. Donaldson K, Stone V. 2003. Current hypotheses on the mechanisms of toxicity of ultrafine particles. Ann Ist Super Sanita. 2003;39(3):405-10.

13. Environment and Climate Change Canada. Guidelines, objectives, codes and practice. Sept 18, 2013.

14. Gabay C, Kushner I. Acute phase proteins and other systemic responses to inflammation. The New Eng J Med. 1999;340(6):448-54.

15. Galatius-Jensen S, Wroblewski H, Emmeluth C, Bie P, Haunsø S, Kastrup J. Plasma endothelin in congestive heart failure: a predictor of cardiac death? J Card Fail. 1996;2(2):71-6.

16. Ghosh JK, Wilhelm M, Su J, Goldberg D, Cockburn M, Jerrett M, et al. Assessing the influence of traffic-related air pollution on risk of term low birth weight on the basis of land-use-based regression models and measures of air toxics. Am J Epidemiol. 2012;175(12):1262-74. 
17. Goldberg MS, Burnett RT, Valois MF, Flegel K, Bailar JC III, Brook J, et al. Associations between ambient air pollution and daily mortality among persons with congestive heart failure. Environ Res. 2003;91:8-20.

18. Grunig G, Marsh LM, Esmaeil N, Jackson K, Gordon T, Reibman J, Kwapiszewska G, Park S. Perspective: ambient air pollution: inflammatory response and effects on the lung's vasculature. Pulm Circ. 2014;4(1):25-35.

19. Guo Y, Lip GYH, Apostolakis S. Inflammation in atrial fibrillation. J Am College Cardiol. 2012;60(22):2263-70.

20. Gurusankar R, Jetha S, Curtin K, Filiatreault A, Maclntyre D, Guenette J, et al. Inhalation of low levels of ambient air pollutants increases blood pressure in healthy subjects in a randomized, placebo-controlled, single blind, crossover trial. Am J Respir Crit care med 183. 2011;2011:A6387.

21. Gurusankar R, Kumarathasan P, Saravanamuthu A, Thomson E, Vincent R. Correlation between saliva and plasma levels of endothelin isoforms ET-1, ET-2 and ET-3. Int J Pept. 2015;2015:828759.

22. Heinrich PC, Castell JV, Andust T. Interleukin-6 and the acute phase response. Biochem J. 1990;265:621-36.

23. Herder C, Baumert J, Thorand B, Martin S, Lowel H, Kolb H, et al. Chemokines and incident coronary artery disease. Arterioscler Thromb Vasc Biol. 2006;26(9):2147-52.

24. Herman WH, Holcomb JM, Hricik DE, Simonson MS. Interleukin-1 beta induces endothelin-1 gene by multiple mechanisms. Transplant Proc. 1999; 31(1-2):1412-3.

25. Jia P, Kao C, Kuo P, Zhao Z. A comprehensive network and pathway analysis of candidate genes in major depressive disorder. BMC Systems Biology. 2011;5(Suppl 3):S12.

26. Johns DO, Stanek LW, Walker K, Benromdhane S, Hubbell B, Ross M, et al. Practical advancement of multipollutant scientific and risk assessment approaches for ambient air pollution. Environ Health Perspect. 2012;120(9): 1238-42.

27. Jung UJ, Choi M. Obesity and its metabolic complications: the role of Adipokines and the relationship between obesity, inflammation, insulin resistance, dyslipidemia and nonalcoholic fatty liver disease. Int J Mol Sci. 2014;15:6184-223.

28. Kaplan GG, Szyszkowicz M, Fichna J, Rowe BH, Porada E, Vincent R, et al. Non-specific abdominal pain and air pollution: a novel association. PLoS One. 2012;7(10):e47669.

29. Karthikeyan S, Thomson EM, Kumarathasan P, Guénette J, Rosenblatt D, Chan T, Rideout G, Vincent R. Nitrogen dioxide and ultrafine particles dominate the biological effects of inhaled diesel exhaust treated by a catalyzed diesel particulate filter. Toxicol Sci. 2013;135(2):437-50.

30. Kaw S, Hecker M, Vane JR. The two-step conversion of big endothelin 1 to endothelin 1 and degradation of endothelin 1 by subcellular fractions from human polymorphonuclear leukocytes. Proc Natl Acad Sci U S A. 1992; 89(15):6886-90.

31. Kazeem A, Olubayo A, Ganiyu A. Plasma nitric oxide and acute phase proteins after moderate and prolonged exercises. Iran J Basic Med Sci. 2012;15(1):602-7.

32. Koenig $W$, Sund $M$, Fröhlich $M$, Fischer $H G$, Löwel $H$, Döring $A$, et al. Creactive protein, a sensitive marker of inflammation, predicts future risk of coronary heart disease in initially healthy middle-aged men: results from the MONICA (monitoring trends and determinants in cardiovascular disease) Augsburg cohort study, 1984 to 1992. Circulation. 1999:99(2):237-42.

33. Kumarathasan P, Vincent $R$, Goegan P, Potvin M, Guenette J. Hydroxyl radical adduct of 5-Aminosalicylic acid: a potential marker of ozone-induced oxidative stress. Biochem Cell Biol. 2001a;79:1-10.

34. Kumarathasan $P$, Goegan $P$, Vincent R. An automated high-performance liquid chromatography fluorescence method for the analyses of Endothelins in plasma samples. Anal Biochem. 2001b;299(1):37-44.

35. Kumarathasan P, Vincent R, Goegan P, Bjarnason S, Guenette J. Alteration in lipid oxidation levels and aromatic hydroxylation in ozone exposed fisher 344 rats. Toxicol Mech Methods. 2002;12:195-210.

36. Kumarathasan P, Blais E, Goegan P, Yagminas A, Guenette J, Adamson IYR, et al. 90-day repeated inhalation exposure of SP-C/TNF-a transgenic mice to air pollutants. Int J Toxicol. 2005;24:59-67.

37. Kumarathasan P, Vincent $R$, Das D, Mohottalage S, Blais E, Blank K, et al. Applicability of a high-throughput shotgun plasma protein screening approach in understanding maternal biological pathways relevant to infant birth weight outcome. J Proteome. 2014;100:136-46.

38. Kumarathasan P, Blais E, Saravanamuthu A, Bielecki A, Mukherjee B, Bjarnason S, et al. Nitrative stress, oxidative stress and plasma endothelin levels after inhalation of particulate matter and ozone. Part Fibre Toxicol. 2015;12:28-45.

39. Langrish JP, Mills NL, Chan JKK, Leseman DLAC, Aitken RJ, Fokkens PHB, Cassee FR, Li J, Donaldson K, Newby DE, Jiang L. Beneficial cardiovascular effects of reducing exposure to particulate air pollution with a simple facemask. Part Fibre Toxicol. 2009;6:8-16.

40. Lee CW, Cheng TM, Lin CP, Pan JP. Plasma haptoglobin concentrations are elevated in patients with coronary artery disease. PLoS one. 2013; 8(10):e76817

41. Lee $\mathrm{SH}$, Hong HR, Han TK, Kang HS. Aerobic training increases the expression of adiponectin receptor genes in the peripheral blood mononuclear cells of young men. Biol Sport. 2015;32(3):181-6.

42. Liu L, Kumarathasan P, Guenette J, Vincent R. Hydroxylation of salicylate to 2,3-Dihydroxybenzoic acid in the respiratory tract: effects of aging and ozone exposure in fisher 344 rats. Am J Physiology (Lung Cell Mol Physiol). 1996;271:L995-L1003.

43. Liu L, Kauri LM, Mahmud M, Weichenthal S, Cakmak S, Shutt R, et al. Exposure to air pollution near a steel plant and effects on cardiovascular physiology: a randomized crossover study. Int J Hyg Environ Health. 2014; 217(2-3):279-86.

44. Liu Y, Goodson JM, Zhang B, Chin MT. Air pollution and adverse cardiac remodeling: clinical effects and basic mechanisms. Front Physiol. 2015;6:162.

45. Maheswaran R, Haining RP, Brindley P, Law J, Pearson T, Fryers PR, et al. Outdoor air pollution and stroke in Sheffield, United Kingdom - a smallarea level geographical study. Stroke. 2005;36:239-43.

46. Manzer R, Dinarello CA, McConville G, Mason RJ. Ozone exposure of macrophages induces an alveolar epithelial chemokine response through IL-1a. Am J Respir Cell Mol Biol. 2008;38(3):318-23.

47. Moreno LO, Copetti M, Fontana A, Bonis CD, Salvemini L, Trischitta V, Menzaghi $C$. Evidence of a causal relationship between high serum adiponectin levels and increased cardiovascular mortality rate in patients with type 2 diabetes. Cardiovasc Diabetol. 2016;15:17.

48. Mustafa SB, Gandhi CR, Harvey SA, Olson MS. Endothelin stimulates plateletactivating factor synthesis by cultured rat Kupffer cells. Hepatology. 1995; 21(2):545-53.

49. Neerhof MG, Khan S, Synowiec S, Qu XW, Thaete LG. The significance of endothelin in platelet-activating factor-induced fetal growth restriction. Reprod Sci. 2012:19(11):1175-80.

50. Pieters N, Koppen G, Van Poppel M, De Prins S, Cox B, Dons E, et al. Blood pressure and same-day exposure to air pollution at school: associations with nano-sized to coarse PM in children. Environ Health Perspect. 2015;123(7):737-42.

51. Pope CA. Respiratory disease associated with community air pollution and a steel mill. Utah Valley Am J Public Health. 1989;79:623-8.

52. Pope CA, Dockery DW. Acute health effects of PM10 pollution on symptomatic and asymptomatic children. Am Rev Respir Dis. 1992; 145:1123-8.

53. Pope CA, Burnett RT, Thurston GD, Thun MJ, Calle EE, Krewski D, et al. Cardiovascular mortality and long-term exposure to particulate air pollution: epidemiological evidence of general pathophysiological pathways of disease. Circulation. 2004;109:71-7.

54. Pope CA, Rodermund DL, Gee MM. Mortality effects of a copper smelter strike and reduced ambient sulfate particulate matter air pollution. Environ Health Perspect. 2007;115:679-83.

55. Pouliou T, Kanaroglou PS, Elliott SJ, Pengelly LD. Assessing the health impacts of air pollution: a re-analysis of the Hamilton children's cohort data using a spatial analytic approach. Int J Environ Health Res. 2008;18:17-35.

56. Rich DQ, Kipen HM, Huang W, Wang G, Wang Y, Zhu P, Ohman-Strickland P, Hu M, Philipp C, Diehl SC, Lu S, Tong J, Gong J, Thomas D, Zhu T, Zhang J. Association between changes in air pollution levels during the Beijing Olympics and biomarkers of inflammation and thrombosis in healthy young adults. JAMA. 2012;307(19):2068-78.

57. Ridker PM, Hennekens $\mathrm{CH}$, Buring JE, Rifai N. C-reactive protein and other markers of inflammation in the prediction of cardiovascular disease in women. N Engl J Med. 2000;342:836-43.

58. Sang L, Miller JJ, Corbit KC, Giles RH, Brauer MJ, Otto EA, et al. Mapping the NPHP-JBTS-MKS protein network reveals ciliopathy disease genes and pathways. Cell. 2011;145(4):513-28.

59. Shields KN, Cavallari JM, Hunt MJO, Lazo M, Molina M, Molina L, et al. Traffic-related air pollution exposures and changes in heart rate variability in Mexico City: a panel study. Environ Health. 2013;12:7-21. 
60. Shutt RH, Kauri LM, Weichenthal S, Kumarathasan P, Vincent R, Thomson EM, Liu L, Mahmud M, Cakmak S, Dales R. Exposure to air pollution near a steel plant is associated with reduced heart rate variability: a randomised crossover study. Environ Health. 2017;16(1):4-13.

61. Sioutas C, Delfino RJ, Singh M. Exposure assessment for atmospheric ultrafine particles (UFPs) and implications in epidemiologic research. Environ Health Perspect. 2005;113:947-55.

62. Skaria T, Burgener J, Bachli E, Schoedon G. IL-4 causes Hyperpermeability of vascular endothelial cells through Wnt5A signaling. PLoS One. 2016;11(5):e0156002.

63. Smith DA, Irving SD, Sheldon J, Cole D, Kaski JC. Serum levels of the antiinflammatory cytokine interleukin-10 are decreased in patients with unstable angina. Circulation. 2001;104(7):746-9.

64. Sprague AH, Khalil RA. Inflammatory cytokines in vascular dysfunction and vascular disease. Biochem Pharmacol. 2009:78(6):539-52.

65. Squadrito GL, Cueto R, Dellinger B, Pryor WA. Quinoid redox cycling as a mechanism for sustained free radical generation by inhaled airborne particulate matter. Free Radic Biol Med. 2001;31(9):1132-8.

66. Sridhar K, Mohaideen JA. Environmental impact and forecast of pollutants from coke oven gas and natural gas combustion. Int J Eng Res Dev. 2012;1 (1):42-25.

67. Stanek LW, Brown JS, Stanek J, Gift J, Costa DL. Air pollution toxicology-a brief review of the role of the science in shaping the current understanding of air pollution health risks. Toxicol Sci. 2011;120(Suppl 1):S8-27.

68. Stec DE, Drummond HA, Vera T. Role of carbon monoxide in blood pressure regulation. Hypertension. 2008:51:597-604.

69. Szomjak E, Der H, Kerekes G, Veres K, Csiba L, Toth J, et al. Immunological parameters, including CXCL8 (IL-8) characterize cerebro- and cardiovascular events in patients with peripheral artery diseases. Scand J Immunol. 2010; 71(4):283-91.

70. Tane N, Inoue H, Aihara M, Ishida H. The effects of endothelin-1 on flap necrosis. Ann Plast Surg. 1995;35(4):389-95.

71. Tedgui A, Mallat Z. Cytokines in atherosclerosis: pathogenic and regulatory pathways. Physiol Rev. 2006;86:515-81.

72. Thomson E, Kumarathasan P, Goegan P, Aubin R, Vincent R. Differential regulation of the lung endothelin system by urban particulate matter and ozone. Toxicol Sci. 2005;88(1):103-13.

73. van Loon JE, Sonneveld MA, Praet SF, de Maat MP, Leebeek FW Performance related factors are the main determinants of the von Willebrand factor response to exhaustive physical exercise. PLoS One. 2014; 9(3):e91687.

74. Villeneuve PJ, Chen L, Stieb D, Rowe BH. Associations between outdoor air pollution and emergency department visits for stroke in Edmonton. Canada Euro J Epidemiol. 2006;21:689-700.

75. Vincent R, Kumarathasan P, Goegan P, Bjarnason SG, Guenette J, Berube D, et al. Inhalation toxicology of urban ambient particulate matter: acute cardiovascular effects in rats. Res Rep Health Eff Inst. 2001a;104:5-54.

76. Vincent R, Kumarathasan P, Mukherjee B, Gravel C, Bjarnason S, Urch B, et al. Exposure to urban particles (PM2.5) causes elevations of the plasma vasopeptides endothelin ET-1 and ET-3 in humans. Am J Resp Crit care med. 2001b;163:A313.

77. Wang CJ, Liu JT, Guo F. (-)-epigallocatechin Gallate inhibits Endothelin-1induced C-reactive protein production in vascular smooth muscle cells. Basic Clin Pharmacol Toxicol. 2010;107:669-75.

78. WHO Report 2016. Ambient air pollution: A global assessment of exposure and burden of disease. p. 1-132. http://apps.who.int/iris/bitstream/10665/ 250141/1/9789241511353-eng.pdf

Ready to submit your research? Choose BMC and benefit from:

- fast, convenient online submission

- thorough peer review by experienced researchers in your field

- rapid publication on acceptance

- support for research data, including large and complex data types

- gold Open Access which fosters wider collaboration and increased citations

- maximum visibility for your research: over $100 \mathrm{M}$ website views per year

At BMC, research is always in progress.

Learn more biomedcentral.com/submissions 